\title{
Przyczyny nieszczelności rurociągu wody amoniakalnej w obszarze połączeń spawanych
}

\section{Causes of pipeline leakage ammonia water near to welded joints}

\section{Streszczenie}

W artykule przedstawiono wyniki badań przeprowadzonych w celu ustalenia przyczyn pękania rurociągu wody amoniakalnej wykonanego ze stali P235GN. Badania wykazały, że przyczyną powstawania pęknięć w pobliżu złączy spawanych jest korozja międzykrystaliczna na skutek działania środowiska agresywnego (siarczek żelazowy). Stwierdzono, że dodatkową przyczyną mógł być brak podgrzewania wstępnego i wyżarzającego połączeń spawanych.

\section{Wstęp}

Po kilku latach eksploatacji w rurociągach odnotowano liczne uszkodzenia poprzeczne na powierzchni wewnętrznej wokół połączeń spawanych. Wykonywane naprawy przez spawanie nie dały pozytywnych wyników. Pęknięcia miały charakter międzyziarnowy i były wypełnione produktami korozji zawierającymi m.in. siarczek żelazawy FeS. Rurociąg został wykonany ze stali niestopowej (konstrukcyjnej) P235GH.

Montaż i połączenia spawane wykonywała firma posiadająca uprawnienia UDT oraz zatwierdzoną instrukcję technologiczną spawania WPS. Połączenia spawane wykonano na zimno bez wyżarzania odprężającego jak dla stali węglowej. Projektant rurociągu nie podał dodatkowych warunków spawania. Badania metalograficzne wykazały, że przyczyną uszkodzenia była korozja naprężeniowa.

Jerzy Dobosiewicz, Wojciech Brunné - Przedsiębiorstwo Usług Naukowo-Technicznych „Pro Novum", Katowice.

\section{Abstract}

The article presents the results of tests conducted to determine the causes of cracking of ammonia water pipe made of steel P235GN. Studies show that the cause of cracks near to welded joints is intergranular corrosion by the action of aggressive environment (iron sulfide). It is found that an additional reason could be the lack of preheating and annealing of welded joints.

\section{Warunki pracy}

Rurociągi wody amoniakalnej pracują w sposób ciągły. Powstająca w procesie kondensacji gazu koksowniczego woda zawiera duże ilości rozpuszczonych związków kwaśnych $\mathrm{H}_{2} \mathrm{~S}, \mathrm{CO}_{2}$ oprócz amoniaku oraz również lotne i nielotne związki amonowe, zawiesiny smół, olejów, fenole, benzol i inne związki smołowe.

\section{Dane techniczne rurociągów}

$$
\begin{array}{ll}
\text { Parametry pracy } & \\
\text { Ciśnienie: } & \\
\text { - ciśnienie robocze } & p_{r}=1,0 \mathrm{MPa}, \\
\text { - ciśnienie próbne } & p_{p}=1,43 \mathrm{MPa}, \\
\text { - temperatura } & t_{r}=80^{\circ} \mathrm{C} . \\
\text { Wymiary: } & \\
\text { - kolana } & \varnothing 108 \times 6,30 \mathrm{~mm}, \\
\text { - prostki } & \varnothing 60,3 \times 3,6 \mathrm{~mm}, \\
\text { - prostki } & \varnothing 114,3 \times 4,0 \mathrm{~mm} .
\end{array}
$$

Środowisko korozyjne:

Zgodnie $z$ danymi projektowymi w wodzie pogazowej dopuszcza się maksymalne stężenie: $10 \mathrm{~g} / \mathrm{dm}^{3} \mathrm{Cl}^{-}$ i $2 \mathrm{~g} / \mathrm{dm}^{3} \mathrm{H}_{2} \mathrm{~S}$. 


\section{Naprężenia}

Dokumentacja techniczna wymienia dwa źródła naprężeń:

- od wydłużeń: $60 \div 80 \%$ dopuszczalnego dla zastosowanej stali, co po przeliczeniu wg danych testowych dla $R_{e}=254 \mathrm{MPa}$ daje:

$$
(254 \mathrm{MPa} / 1,5) \times 0,8=135 \mathrm{MPa}
$$

- od ciśnienia: dla $p_{r}=1 \mathrm{MPa}$ wynoszą $\mathrm{w}$ zależności od wymiarów rur odpowiednio:

- $\varnothing 108 \times 6,30 \mathrm{~mm}=>8,5 \mathrm{MPa}$,

- $114,3 \times 4,0 \mathrm{~mm}=>9,0 \mathrm{MPa}$,

- $\varnothing 60,3 \times 3,6 \mathrm{~mm}=>8,3 \mathrm{MPa}$.

W warunkach spawania wskazanych przez projektanta nie ma informacji dot. podgrzewania wstępnego oraz wyżarzania odprężającego, co wynika z gatunku materiału i grubości ścianki rur rurociągu.

\section{Charakter i umiejscowienie pęknięć}

Uszkodzenia w postaci pęknięć obwodowych występowały najczęściej na:

- króćcach do pomiarów AKPiA (rys. 1 i 2),

- spawanych kolanach segmentowych (rys. 3),

- odcinkach prostych w strefie spoin kątowych, tzw. boczników (rys. 4).

Początek pęknięć zlokalizowany był na powierzchni wewnętrznej w pobliżu połączeń spawanych lub pod nimi oraz przy spoinach połączeń kołnierzowych.

\section{Badania makroskopowe wykazały, że:}

- pęknięcia w rejonie spoin obwodowych występuja w znacznej odległości od połączenia spawanego (rys. 5),

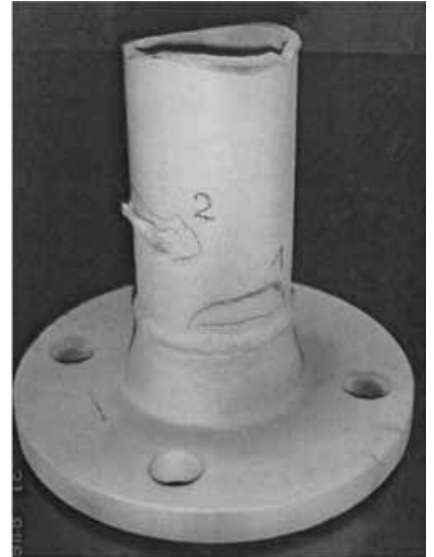

Rys. 1. Połączenie czołowe z kołnierzem

Fig. 1. The butt joint with flange

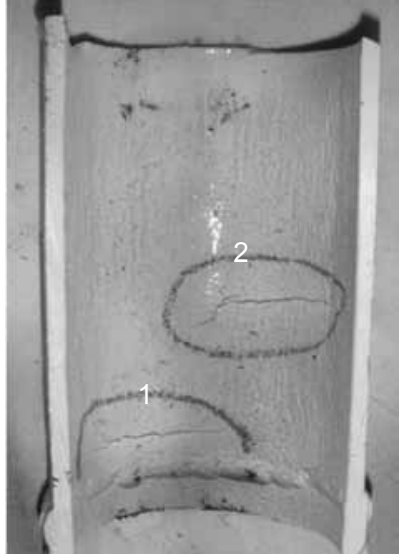

Rys. 2. Obwodowe pęknięcia rurociągu od strony wewnętrznej w pobliżu spoin obwodowych czołowych (1) i pachwinowych (2) Fig. 2. Circumferential cracks on the inner side of the pipeline near the butt circumferential joints (1) and fillet weld (2)
- pęknięcia pod spoina pachwinową bocznika umiejscowione są poza strefą wpływu ciepła (SWC) (rys. 6).

\section{Badania metalograficzne}

Badania metalograficzne wykonano na przekrojach poprzecznych pęknięć oraz spoin. W wyniku badań stwierdzono, ze w rejonie wszystkich pęknięć struktura metalu jest ferrytyczno-perlityczna z wyraźną

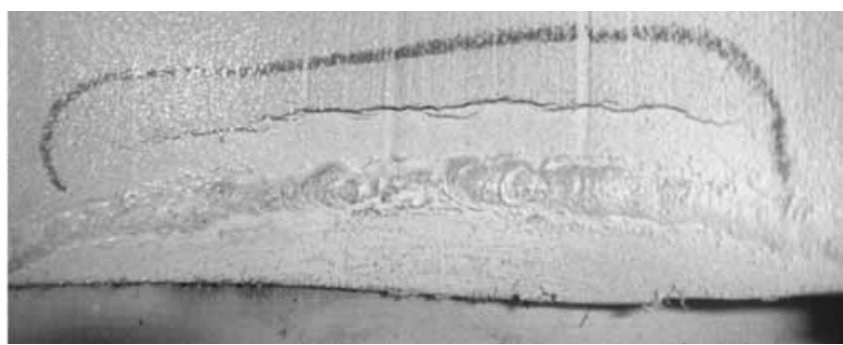

Rys. 3. Kolano segmentowe, pęknięcie w okolicy spoiny czołowej Fig. 3. Knee segment, rupture near to a butt weld

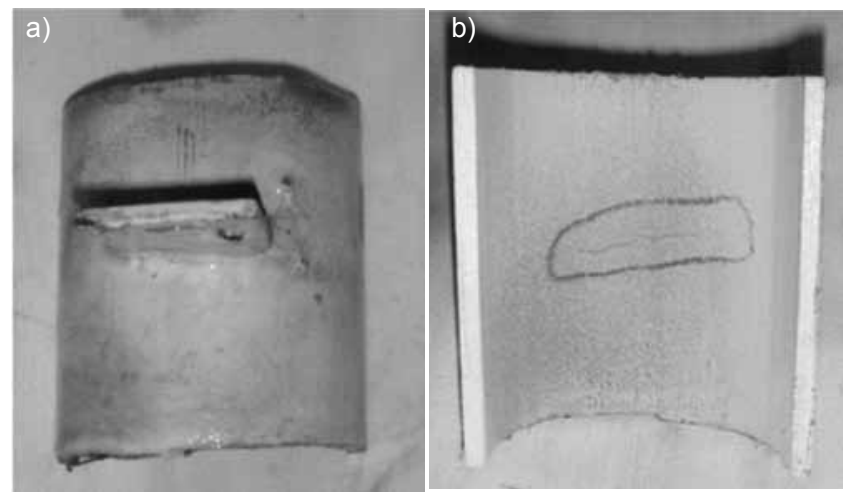

Rys. 4. Napoina pachwinowa bocznika do galwanicznego łączenia elementów rurociągu (a) i pęknięcia obwodowe pod bocznikiem (b). Fig. 4. Padding weld on the shunt to galvanic joining of elements of the pipeline (a) and circumferential cracks in a shunt (b)

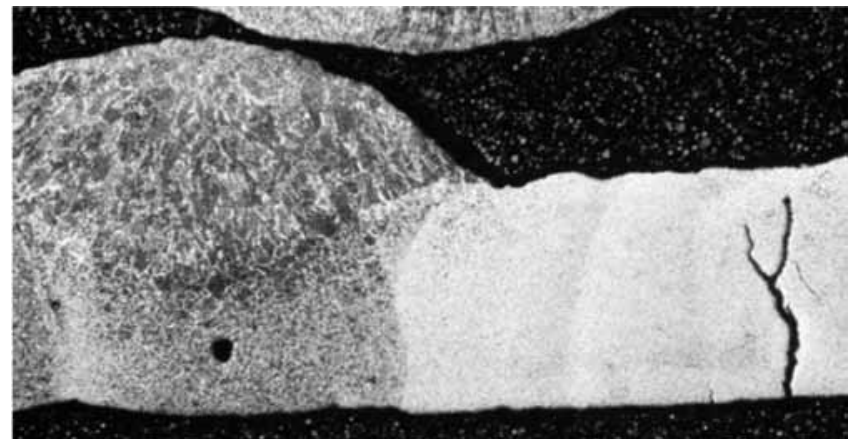

Rys. 5. Połączenie kołnierzowe - pęknięcia od strony wewnętrznej Fig. 5. Flange joint - cracks on the inside

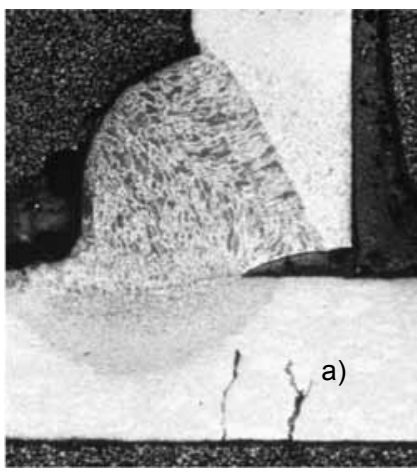

Rys. 6. Połączenie bocznika z rura - pęknięcia od strony wewnętrznej

Fig. 6. The joint of shunt and pipe - cracks on the inside 
pasemkowatością (rys. 7), a pękanie ma charakter międzyziarnowy (rys. 8).

\section{Pomiary twardości}

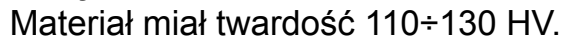

\section{Badania osadów}

Sprawdzono metodą punktową skład chemiczny osadu pobranego z pęknięcia. W wyniku badania stwierdzono obecność znacznej ilości związków siarki (rys. 9).

\section{Badania wody amoniakalnej}

Badania wody amoniakalnej wykazały, że w czasie prowadzenia badań stężenie siarkowodoru nie przekroczyło $0,5 \mathrm{~g} / \mathrm{dm}^{3}$.

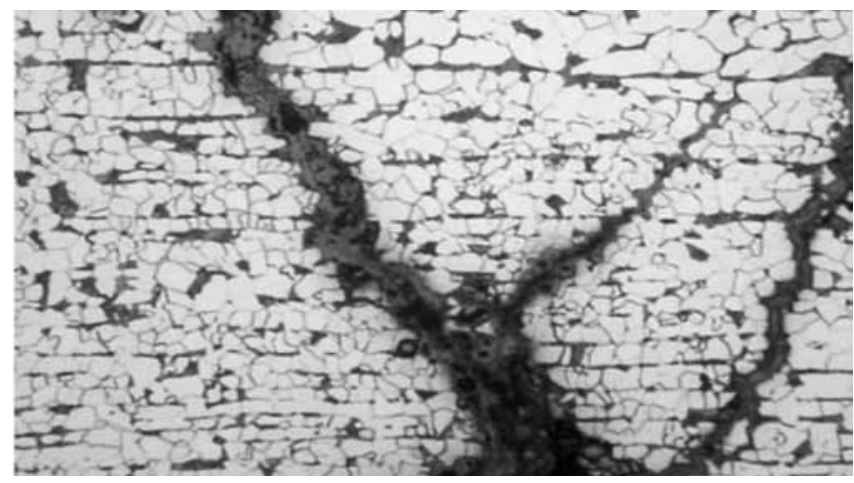

Rys. 7. Fragment a $z$ rys. 6 , pow. $100 x$

Fig. 7. Fragment a $z$ fig. 6 , magn. $100 x$

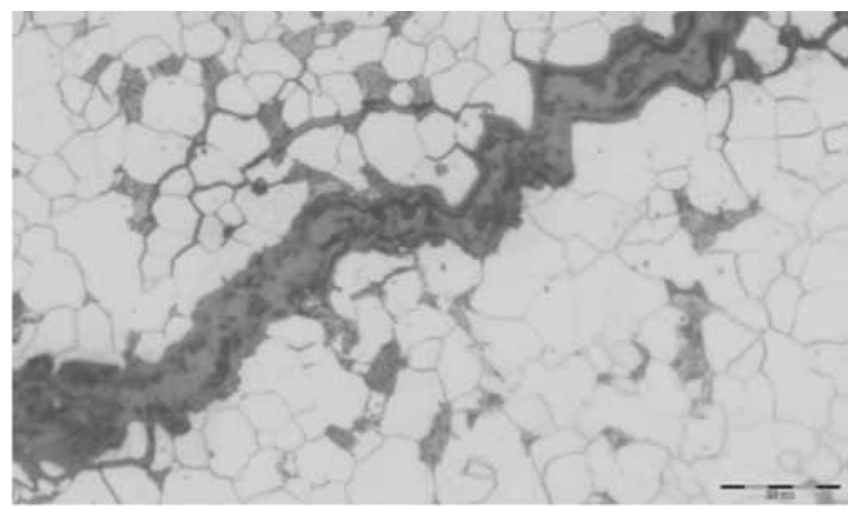

Rys. 8. Pęknięcie przebiegające po granicach ziarn

Fig. 8. Crack extending on the grain boundaries

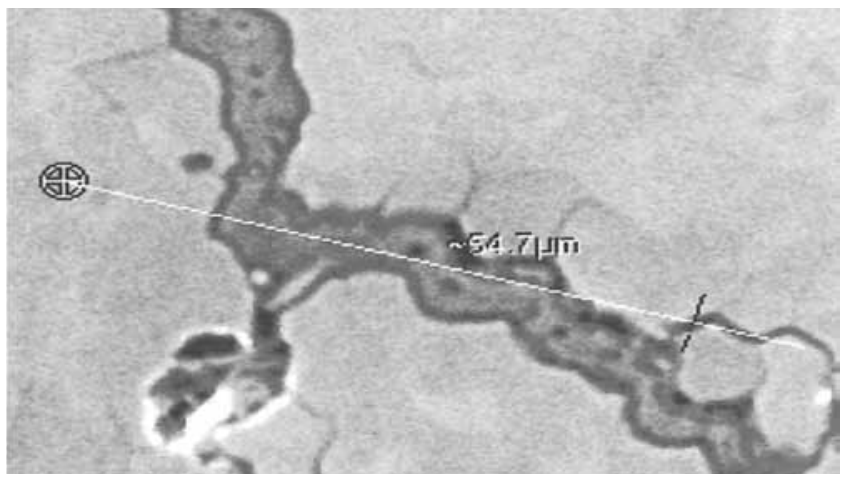

Rys. 9. Miejsca badań punktowych osadów w pęknięciach

Fig. 9. Location of point of sediment in the cracks

\section{Podsumowanie}

Rurociąg został wykonany ze stali węglowej P235GN, a połączenie spawane wykonano bez podgrzewania wstępnego i wyżarzania odprężającego zgodnie z uprawnieniami UDT - wykonawcy montażu dla tego gatunku stali.

Występujące uszkodzenia miały charakter poprzeczny w stosunku do głównej osi rurociągu i brały swój początek na powierzchni wewnętrznej w pobliżu spoin, szczególnie pachwinowych, łączących elementy „obejść” galwanicznych z powierzchnią rury.

Wszystkie pęknięcia przebiegały między ziarnami (charakter międzykrystaliczny) i były powodowane korozją międzykrystaliczną, która występuje w przypadku:

- działania naprężeń rozciągających (własnych lub przyłożonych),

- obecności środowiska agresywnego (np. $\mathrm{H}_{2} \mathrm{~S}$ ),

- materiału podatnego na działanie $\mathrm{H}_{2} \mathrm{~S}$ (woda amoniakalna zawierająca $\mathrm{H}_{2} \mathrm{~S}$ ).
W rurociagach wykonanych ze stali węglowych po niezbyt długim okresie eksploatacji często występują pęknięcia międzykrystaliczne. Jest to pękanie naprężeniowe, siarczkowe pojawiające się w strefach SWC lub w ich pobliżu. W stali o strukturze ferrytyczno-perlitycznej o stosunkowo niskiej twardości często pojawia się również w materiale rodzimym.

Gdy twardość obszaru złącza spawanego lub w miejscu spoin przekracza dopuszczalną wartość 250 HV, należy zgodnie z PN-EN ISO 15156-2:2008 spawany element poddać wyżarzaniu odprężającemu.

Przyczyną uszkodzenia było prawdopodobnie przekraczanie dopuszczalnej wartości stężenia $\mathrm{H}_{2} \mathrm{~S}$ w wodzie amoniakalnej, co mogło mieć miejsce w czasie rozruchu urządzenia lub okresowo w czasie eksploatacji. Dodatkowym czynnikiem sprzyjającym inicjacji pękania był sposób montażu (brak podgrzewania wstępnego i wyżarzania odprężającego połączeń spawanych).

\section{Literatura}

[1] Uhlig H.: Korozja i jej zapobieganie, Warszawa, WNT 1976.

[2] Tasak E.: Pękanie korozyjne stali niestopowych i stopowych - problemy uszkodzeń korozyjnych instalacji w przemyśle chemicznym. Seminarium naukowo-techniczne UDT Oddz. Kraków, 06.2010. 